\title{
"PANDEMIC" CONCEPT IN THE ENGLISH LANGUAGE
}

\section{Yuliia Sharapanovska}

Postgraduate Student at the Department of Romance-Germanic Philology and Foreign

Language Teaching, International Humanitarian University, Ukraine

e-mail: yuliia.sharapanovskaya@gmail.com,orcid.org/0000-0002-5397-2941

\section{Summary}

The term "concept" has a number of definitions, but there is no universal one. The concept is one of the basic phenomena of modern linguistics. The concept is a mental formation, which is the result of a person's cognitive activity and contains information about the objects of the surrounding reality. The concept can be defined as is a global unit on the mental level that represents and structures human knowledge of both material and spiritual worlds. The concept content can be divided into its linguistic significance and a cultural interpretation, so the concept is often called a unit of knowledge, an abstract idea or a mental symbol. The concept of "pandemic" can be considered a key element included in the linguistic picture of the world of every language nowadays. The structure of the concept is represented by three basic components: in the image, information content and interpretation field. The concept of "Pandemic" can be classified into into 7 subgroups, the lexical units of which are in the center of the lexical-semantic group and are close to the value of the nucleus, which can in its turn be subdivided into 3 subgroups.

Keywords: conceptual picture of the world, semantic groups, verbalization, nomination, lexemes, lexical units, lexical value.

\section{DOI: https://doi.org/10.23856/4710}

\section{Introduction}

Studying the concept dates back a long time ago. Its origin and primary development are associated with the name of P. Abelara (XII century), who believed that the concept is a form that is capable of covering any meaning, a set of concepts in the human mental sphere, formed during the perception and use of speech.

The term "concept" in modern linguistics is interpreted extremely widely and ambiguous. The information content of the concept consists of a minimum number of cognitive features that determine the most important and distinctive features of an object or phenomenon. The interpretation field includes cognitive features that interpret the information content of the concept. A distinctive feature of the interpretation field is the presence of cognitive symptoms that contradict each other. The concept structure can only be described when its content is defined and described, that is, cognitive features of the concept exist.

When studying the concepts that are units of the mental level and are not subject to direct observation, scientists are appealing to the expression plan: words, phrases, sentences, text. The word as the name of the concept with its lexical value reflects the most significant features of the concept.

All conceptual information and representation of a person about the surrounding world form a so-called conceptual picture of the world stored in public and individual consciousness in the form of a set of concepts called conceptosphere. The conceptual picture of the world is 
objected in the language, creating, accordingly, the linguistic picture of the world, which is narrower in content and reflects the most significant fragments of the conceptual.

Concept is a universal, global unit of mental level, quantum clearly and consistently structured human knowledge of material and spiritual worlds; the means of expression and explanation of which is the language; fulfilling the evaluation function, closely related to the mind, memory, culture and psyche, the concepts are not only anticipated, they are felt. The concept is also a discrete unit of collective consciousness, which is stored in the national memory of the language of the language in the vocabulary.

Among the researchers there is a popular statement that the current language cannot be considered irrespective of its direct media - a person. The leading direction of modern anthropocentric linguistics development is a cognitive approach, which is why the clear definition of the term "concept" as the main for this field of linguistics is extremely important. The scientists' attention is, first of all, attracted to the concepts related to the culture of people, which conveys the peculiarities of their collective consciousness: life, death, man, love, happiness, etc. The theoretical and practical issues of the concept in modern linguistics have been considered by O. Babushkin, O. Kubryakova, S. Askoldov, D. Lihachov, Yu. Stepanov, S. Zabotinskaya, M. Boldirev, Z. Popova, J. Sternin, S. Vorkachev, O. Selivanova and others.

\section{Concept in linguistics}

In linguistics the concept, unlike the word, has a more complex structure. The content of the concept is divided into its linguistic significance and a cultural interpretation, so it is often called a unit of knowledge, an abstract idea or mental symbol. Among the researchers there is a common idea that modern language cannot be considered irrespective of the direct medium of this language. The leading direction of modern anthropocentric linguistics development is a cognitive approach, so it is extremely important to clearly define the term "concept" as the main thing for this branch of linguistics. As mentioned above, "concept" does not have universal definitions in linguistics, despite the fact that many linguists were and still are engaged in its study.

The concept is one of the basic phenomena of modern linguistics. The concept is a mental formation, which is the result of a person's cognitive activity and contains information about the objects of the surrounding reality. The concept and interpretation are correlated as a part and the whole: the interpretation contains only the most significant features of the object and are the base layer of the concept. The content, in addition to the meaning, includes chosen, emotional, evaluative, as well as cultural and national information (Angelova, 2004:4).

In modern linguistics there are three main approaches to understanding the meaning of "concept":

1) linguistic (S. Askoldov, D. Likhachov, V. Kolesov, V. Telia): since the concept exists for each vocabulary value, then it should be considered as an algebraic expression of meaning. In general, supporters of this direction understand the concept as all the potential of the word meaning together with its connotative element;

2) cognitive (Z. Popov, J. Sternin, O. Kubryakova): the concept is a phenomenon of mental character. Representatives of the cognitive approach are included in the concept of mental phenomena and interpret it as an operational meaning of memory, mental lexicon;

3) culturological (Yu. Stepanov, G. Slyshkin): culture on the whole is understood as a set of concepts and relations between them. Concept is the main part of culture in the human mental world. Scientists who adhere to this approach are convinced that when studying the 
concept, attention should be paid to the cultural information that it transmits. The concept here is defined as a basic unit of culture and is its concentration.

Thus, at the present stage in linguistics it is impossible to track a single opinion in the interpretation of the meaning of "concept" and its ability to characterize the surrounding world. Regardless of the types of concepts, all of them are structural links, building material of the conceptosphere of a certain language, in which smaller formations can be distinguished.

Researchers note that the concept, as a category that is one of the most important for a number of spheres, is characterized by its heterogeneity. Specific and abstract, individual and group concepts are allocated; their division can be continued to smaller units. In detail, the typology of concepts can be considered on the following features:

1) mental pictures (specific visual images - e.g. "German Shepherd" dog);

2) schemes (less detailed images - e.g. home as a house);

3) hyperonyms (very generalized images - e.g. wood);

4) frames (a set of associations that we keep in memory - e.g. New Year);

5) insights (knowledge of the functional purpose of the subject - e.g. a fork);

6) scenarios (knowledge of the plot development of events - e.g. wedding);

7) kaleidoscopic concepts (a set of scenarios and frames that are associated with feelings e.g. happiness) (Vezhbitskaya, 1997: 43-67).

Linguists emphasize that the concepts, which are a consequence and the result of a person's cognitive experience, are clearly structured, have a specific form of existence. According to G. Slyshkin: "Concepts reflect the content of knowledge gained, experience, results of all human activity and the results of its knowledge in the form of certain units," quantum "knowledge." According to the researcher, concepts are units, meanings that man operates in the thinking process. In the minds, they are formed in several ways: on the basis of sensual experience; based on practical activity; on the basis of cognitive (experimental, theoretical) scientific activity; on the basis of mental activity during transactions with already known concepts; based on communication (verbal, nonverbal) (Slyshkin, 2004: 23-25).

The cognitive definition of the concept essence is based on several basic principles: the concept is able to form and preserve knowledge of the world, reflect the results of human cognitive activity; concepts as units of thinking level exist in the form of certain information elements; it is a means of forming, verbalization of concepts in human consciousness; when creating concepts with auxiliary sources, there are sensual experience, practical activities, visibility.

By definition after O. Selivanova, the concept is the information structure of consciousness, a variety of special memory units, which contains a set of knowledge about the object of knowledge, verbal and non-verbal, acquired by the interaction of five mental functions of consciousness and an extra-aware. The nucleus of the concept is the concept fixed in the form of proposal structures and marked with a certain nominative unit. Concepts originate during cognitive activity, reflect and summarize human experience and consciousness, are realistic, bringing information under certain categories and classes produced by society. The word is a means of accessing conceptual knowledge, but it can represent different concepts, so it is a rather compact conceptualization means (Selivanova, 2006:256).

A. Zagnitko emphasizes the universality of the concept and language as the most important means of its material expression, implementation: "The concept is a global unit of thinking activity, it is a quantine of structured knowledge. Concepts are mostly inherent in universalism, their expression cannot be limited only in the language, but the latter appears one of the most powerful means of manifestation in particular and the conceptosphere in general" (Zagnitko, 2010:12). 
Folk, national culture determines the deep, expressive content of concepts; the word is a means of their verbalization, degradation. The significance of specific linguistic means (lexeme, phraseologic unit, expressions) leads to the emergence of concepts in human consciousness. At the same time, personal and cultural and historical experience significantly expands the limits of formation and perception of concepts. If the culture of the people who are the speakers of the language expands, diverse, as a consequence, the structure of a particular concept is also complicated, becomes clearer and brighter pronounced. The linguistic cultural view is based on the accumulation (cumulative) function of language, by which it is directly preserving and transferring popular experience from generation to generation.

Consequently, today there are a huge number of definitions of the term "concept".

At the same time, among all definitions can be distinguished by certain common features by forming a separate, generalized definition: the concept is a universal, global unit of mental level, the quantum clearly and consistently structured human knowledge of the material and spiritual world that surrounds it; means of expression and explanation of which is the language; by performing an estimated function, closely linked to the mind, memory, culture and psyche.

\section{Pandemic as a linguistic concept}

The concept of "pandemic" is considered socially important, especially in the current situation. This is a key element included in the linguistic picture of the world of almost every language today. This concept consists of enormous and most important mental formation in the naive and national language picture of the world. The naive speech picture of the world serves as the basis for the formation of a national picture of the world and the main mechanism of national thinking.

In any language, the concept must primarily have a form - word: verbal shape or verbalization. Lexical units that relate to the conceptual space of the concept are called verbalizers.

The concept verbalizers can be distributed to various components of the group, which some linguists call nominative fields of the concept. The term "field" itself can be considered synonymous to the term "group" and distinguish lexical, grammatical, syntagmatic, associative and other groups or fields. The nominative field is seen as a "set of linguistic means that lens (verbalize, represent) the concept in a certain period of development of society" (Popova, 2007: 66).

To such means they include direct nominations of the concept, derivatives (portable) nominations of the concept, single words, contextual synonyms, phraseologisms that include the name of the concept, paremia, metaphorical nominations, stable comparison with keyword, free phrases that are nominated by certain features that characterize concept, associative field, subjective verbal definitions, vocabulary interpretations of linguistic units, dictionary articles in encyclopaedias and reference books, thematic (scientific), journalistic or artistic texts, collection of texts (subject to explication or discussion of complex, abstract or individualauthor's concepts) (Popova, 2007: 69-71).

The complex method of studying the lexical-semantic group "Pandemic" in English is realized through a combination of general scientific and linguistic methods and is based on the principle of systemicity to study the object, which involves the use of a phased analysis of the language material.

The main verbalizers of the Concept "Pandemic" are primarily the corresponding lexemes, for example: Pandemic, Pandemia, disease, virus, coronavirus, COVID, COVID-19, SARS-COV-2. 
The core of the lexical-semantic group is the lexeme "Pandemic". First of all, we will analyze the definitions given by directories, dictionaries and information sites.

According to the official definition of the World Health Organization, Pandemic is "an epidemic occurring worldwide, or over a very wide area, crossing international boundaries and usually affecting a large number of people". The classical definition does not include anything about the immunity of the population, the virology or severity of the disease. Based on this definition of a pandemic, it can be argued that annually in the southern and northern hemispheres a pandemic occurs, because seasonal epidemics cross international borders and affect a large number of people.

According to the Cambridge dictionary, the term "pandemic" has the following definition: "a pandemic is an occurrence of a disease that affects many people over a very wide area".

The concept of pandemic also includes a number of nominee divisions: various grammatical forms of the word "pandemic" (Pandemic, Pandemics, Pandemical, Pandemically), phrases with the word "Pandemic" (Global Pandemic, Hazardous Pandemic, New Pandemic, Dangerous Pandemic); Contextual synonyms of the word "Pandemic" (Coronavirus, COVID-19, SARS-COV-2, a new disease); words associated with pandemic that can be divided into groups and subgroups.

\section{Classification of "pandemic"}

The material analysis showed that most of the selected lexemes (140 units) can be divided into 7 subgroups, the lexical units of which are in the center of the lexical-semantic group and are close to the value of the nucleus:

1) lexical units to indicate the variations of the virus (7): SARS-COV-2, Covid-19, Coronavirus, Covid, a virus, a new disease, infectious disease;

2) lexical units to indicate the symptoms of the disease (19): Coronavirus symptoms, fever and tiredness, (new) continuous cough, breathing difficulties, respiratory symptoms, the onset of symptoms, fever, cough, fatigue, loss of smell, shortness of breath, pneumonia, exposure, acute respiratory distress symptoms, to develop symptoms, to catch coronavirus, to confirm positive, to become critically ill, to be most contagious;

3) lexical units to indicate a person's health condition before the disease (8):

underlying health conditions, vulnerable people, chronic diseases, HIV, low immunity, cancer, diabetes, elderly age;

4) lexical units to indicate methods of treatment (15): the Coronavirus fight, Coronavirus emergency, Coronavirus service, subcutaneous injections, intravenous infusion, PEP (postexposure prophylaxis), artificial lung ventilation, to tackle the virus, symptomatic treatment, supporting therapy, antiviral treatment, to treat people, to activate emergency-response mechanisms, to scale-up emergency-response mechanisms, to struggle with the virus;

5) lexical units to indicate how to prevent disease (56): quarantine, lockdown, vaccination, inoculation, social distancing, isolation, self-isolation, unnecessary journeys, essential shopping, public gatherings sanitizer gel, stockpiling, shielding, public health, social restrictions, reasonable/unreasonable excuses, Covid restrictions, public health emergency of international concern, aggressive antibody testing, screening tests, positive cases, shelter-in place provisions, test kits, testing process, procurement of vital medical equipment, a mask, a face mask, a medical mask, personal protective equipment, alcohol-based hand rub, frequent hand-cleaning, disinfection vehicles, health checks, low stocks at supermarkets, contaminated surfaces, preventive measures, hand washing, maintaining distance, curfews, stay-at-home 
orders, workplace hazard control, facility closures, to trace contacts, to protect oneself, to communicate about the risk, to stay away from other people, to seek medical advice, to be tested for the virus, to stay at home, to wear medical masks, to remove the mask, to discard the mask, to dispose the mask, to avoid infection, to penetrate masks;

6) lexical units to indicate the methods of disease spreading (16): pandemic, global pandemic, epidemic, SARS-CoV-2 transmission, the coronavirus outbreak, global spread, the spread of the virus, Coronavirus cases, hardest-hit countries, Chinese lab boss, a bounce-back of the disease, prevalence of the virus, a speculative theory, the trajectory of the outbreak, a route of transmission, to be linked to the previous cases;

7) lexical units to indicate the social consequences of the disease (19): severe global socioeconomic disruption, the largest global recession, misinformation, disinformation, postponement of events, cancellation of events, widespread supply shortages, panic buying, to choke a fragile economy, to expand coronavirus policy, to reopen business, to roll back restrictions, to push hospitals to over capacity, to step up the massively important testing program, to bulk-buy a huge supply, to implement travel restrictions, to increase testing capacity, mortality rate, fatality rate.

The least numerical group is a group of lexical units to indicate variations of the virus / disease name ( 7 units that is about 5\%), which can be logically explained by the fact that it is a single infection (SARS-COV-2 or COVID-19), which led to Pandemic in 2020. Existing options are explanations (a new disease), simplifying (Coronavirus, COVID) or even euphemisms (infectious disease, a virus).

The next largest group is a group of lexical units to indicate a person's health condition before the disease ( 8 units that is about $6 \%$ ) that can lead to symptoms and make a severe disease (diabetes, HIV, cancer and others).

A much wider group (15 units that is about 10\%) is a group of lexical units to indicate methods of treatment that is quite dynamic and steadily replenished with new units (subravenous infusion, PEP (post-exposure prophylaxis), artificial lung ventilation, to tackle the virus, symptomatic treatment and others).

A group of lexical units is very close to it in the designation of methods for spreading the disease (16 units that is about 11\%) (SARS-Cov-2 transmission, the Coronavirus outbreak, global spread, the spread of the virus, Coronavirus cases, hardest-hit countries and others).

The following two groups are equivalent in quantity (19 units that is about $14 \%$ in each): lexical units to indicate symptoms of the disease (cough, fever, fatigue, loss of smell and others) and lexical units to indicate social consequences of the disease (severe global socioeconomic disruption, the largest global recession, panic buying, cancelation of events, widespread supply shortages and others).

The most numerical group that consists of 56 units (about $40 \%$ ) is a group of lexical units to indicate methods how to prevent the disease (quarantine, lockdown, vaccination, inoculation, social distancing, isolation, public gatherings and others). This group has significantly expanded during the period from May to December 2020, which is explained by the fact that the methods of preventing infection are the main goal in all countries of the world.

The peripheral of the field includes units that are the most distant in their meaning to the nucleus. All fixed lexemes can be subdivided into 3 subgroups that include the following lexical units:

- subgroup 1 - lexical units that arouse feelings associated with excitement of possible infection of a person or his loved ones (nervousness, fear, inevitability, overexcitement, restlessness); 
- subgroup 2 - words to support the types of professional activities that have been difficult through a pandemic (online conferences, Zooming, Skype work, contactless delivery, distance learning);

- subgroup 3 - lexical units denoting a person's attitude to a pandemic and warning and fight against it (conspiracy theory supporters, Antivax, Anti-Vaccination League, Anti-Covid society members).

\section{Conclusions}

An important feature of the concepts is the focus on the value guidelines of the people. Value as a specific social definition of objects and phenomena of reality, taking into account their significance, positive or negative importance to humans and society is an important element of any linguistic culture concept. In the language marker, the value of the phenomenon or object becomes a nominative density of the group of words that denote it. The values are based on the definition of the phenomenon significance in human life. They encode a special perception of the world and the person himself in it. The meanings arise as individual, but if they share a large number of people, they become universal and acquire the status of values. In this case, the value filling of the concept largely determines its national specificity.

The structure of the concept is represented by three basic components: in the image, information content and interpretation field. The image (perceptual and cognitive) is formed by cognitive features of the subject or phenomenon, or as a result of reflection of the senses or comprehension of reality through the metaphor. The information content consists of the most significant cognitive features that determine the characteristics of the subject. The information field does not include the evaluation features of the concept attributed to the sphere of interpretation. Interpretation content is formed on the basis of rethinking the main content of the concept and reflects cognitive signs of evaluation and interpretation. The information field is inhomogeneous and all cognitive signs, it is structured, are divided into several baseline zones: encyclopedic (cognitive signs arising on the basis of experience or study), utilitarian (cognitive signs that reveal the utilitarian attitude to denotate), regulatory (cognitive signs., regulating behavior of people), general evaluation (cognitive signs of concept evaluation), socio-cultural (cognitive signs of the concept reflecting its connection to the cultural environment of the people), paraemine (cognitive signs of the concept recorded in proverbs and sayings) etc.

The contents of the concept are interpreted as a set of all cognitive signs of the concept. The content of the concept is organized according to the field principle: the core of the concept - the near periphery - the extreme periphery. The place of the cognitive feature in the field structure of the concept is determined by the brightness of the feature and is regulated by the following rule: the brighter the cognitive sign, the closer it is to the nucleus. Thus, the kernel of the concept is often formed by cognitive characteristics, transmit its content, the periphery is signs of a subjective nature that express the attitude towards it in a variety of situations of communication.

The concept of "Pandemic" is a global concept that is currently widening, so, its components are still changing. This concept is becoming a universal one as it has very similar structure in different countries and, as a result, in different languages. The prospective is a contrastive research of the concept of "Pandemic" in two languages. 


\section{References}

1. Angelova M. M. "Kontsept" v sovremennoy lingvokul'turologii // Aktual'nye problemy angliyskoy lingvistiki i lingvodidaktiki. Sbornik nauchnykh trudov. [Actual problems of linguistics and linguistic didactic]. Issue 3. M., 2004. P. 3-10. [in Russian].

2. Vezhbitskaya A. Yazyk. Kul'tura. Poznanie / Per. s angl. / Otv. red. M. A. Krongauz. [Culture. Language. Perception.] / Translated from English / Edited by M. A. Krongauz. Introduced by E. V. Paducheva. M. : Russkie slovari, 1997. 416 p. [in Russian].

3. Zaghnitko, A. P. Klasyfikacijni typologhiji konceptiv / A. P. Zaghnitko // Linghvistychni studiji : zb. naukovykh pracj. [Classificational typology of concepts // Linguistic studies/ Donetsk national university. Donetsk: DoNNU, 2010. Issue 21. P. 12-21. [in Ukrainian].

4. Popova Z. D., Sternin I. A. Semantiko-kognitivnyy analiz yazyka. [Semantic cognitive analysis of the language. Voronezh : «IstokI», 2007. 250 p. [in Russian].

5. Slyshkin G. G. Ot teksta k simvolu: lingvokul'turnye kontsepty pretsedentnykh tekstov $v$ soznanii $i$ diskurse. [From the text to the symbol: linguistic cultural concepts of precedent texts in consciousness and discourse]. Link: http://www.vspu.ru/ axiology/ggs.htm/ [in Russian].

6. Selivanova O.O. Suchasna linghvistyka: terminologhichna encyklopedija. [Modern linguistics: encyclopedia of terminology]. Poltava: Dovkillya, 2006. 716 p. [in Ukrainian]. 